\title{
Correction to: Exploring Epidemiological Behavior of Novel Coronavirus (COVID-19) Outbreak in Bangladesh
}

\author{
Samrat Kumar Dey ${ }^{1}$ (D) $\cdot$ Md. Mahbubur Rahman ${ }^{2} \cdot$ Umme Raihan Siddiqi $^{3} \cdot$ Arpita Howlader $^{4}$
}

Published online: 15 September 2020

(C) Springer Nature Switzerland AG 2020

\section{Correction to: SN Comprehensive Clinical Medicine https://doi.org/10.1007/s42399-020-00477-9}

The original version of this article unfortunately contained a mistake. All the images (Figs. 1, 2, 3 and 4) used in that article were the old ones.

The original version has been corrected.

Publisher's Note Springer Nature remains neutral with regard to jurisdictional claims in published maps and institutional affiliations.

The online version of the original article can be found at https://doi.org/ 10.1007/s42399-020-00477-9

Samrat Kumar Dey

sopnil.samrat@gmail.com

Md. Mahbubur Rahman

mahbub.rahman.cse@gmail.com

Umme Raihan Siddiqi

u.raihan.siddiqi@gmail.com

Arpita Howlader

arpita.cce.pstu@gmail.com
Department of Computer Science and Engineering (CSE), Dhaka International University (DIU), Dhaka 1205, Bangladesh

2 Department of Computer Science and Engineering (CSE), Military Institute of Science and Technology (MIST), Mirpur Cantonment, Dhaka 1216, Bangladesh

3 Department of Physiology, Shaheed Suhrawardy Medical College (ShSMC), Dhaka 1207, Bangladesh

4 Department of Computer and Communication Engineering (CCE), Patuakhali Science and Technology University (PSTU), Dumki, Patuakhali 8602, Bangladesh 